\title{
Role of the SIK2-p35-PJA2 complex in pancreatic $\beta$-cell functional compensation
}

\author{
Jun-Ichi Sakamaki, Accalia Fu, Courtney Reeks, Stephen Baird, Chantal Depatie, Mufida Al Azzabi, \\ Nabeel Bardeesy, Anne-Claude Gingras, Siu-Pok Yee and Robert A. Screaton
}

\section{CORRIGENDUM}

Nat. Cell Biol. 16, 234-244 (2014); published online 23 February 2014; corrected after print 26 February 2014

In the version of this Article originally published, the two labels 'SIK2' in Fig. 5g should have read 'PJA2'. This error has now been corrected in the online versions of the Article.

\section{ERRATUM}

Nat. Cell Biol. 16, 234-244 (2014); published online 23 February 2014; corrected after print 5 March 2014

In the version of this Article originally published, 'CDK5R1; also known as p53' in the last sentence of the Introduction should have read 'CDK5R1; also known as p35'. This error has now been corrected in the online versions of the Article.

\section{ERRATUM}

\section{Interplay of RhoA and mechanical forces in collective cell migration driven by leader cells}

\author{
M. Reay, M. C. Parrini, O. Cochet-Escartin, B. Ladoux, A. Buguin, S. Coscoy, F. Amblard, J. Camonis \\ and P. Silberzan
}

Nat. Cell Biol. 16, 217-223 (2014); published online 23 February 2014; corrected after print 26 February 2014

In the version of this Article originally published there were some errors:

The second citation of reference 1 in the first sentence of the main text should have been of reference 2 ( $\ldots$...or by the release of a physical barrier $\left.^{2} . ..\right)$.

The present addresses of B. Ladoux were missing the area codes ('Paris F75205' and '117411 Singapore').

The caption of Fig. 1d-f should have read: '(d,e) Force profiles in the parallel and perpendicular directions resulting from averaging forces for 22 and 12 fingers from 15 and 10 independent experiments respectively. The thick red line is the average profile, the coloured area represents the standard deviation. (f) Schematic representation of the direction of the forces: the leader cell exerts a stable traction longitudinal force whereas the forces in the fingers are highly dynamic and can be positive or negative (red arrows). The side edges exert a centripetal force (green arrows). Fingers were composed of typically 30 cells.'

In the first sentence of the second paragraph under the heading 'Migration fingers are mechanical global entities', the figure citation should have read 'Fig. 1d,e'.

The first part of the caption of Fig. 3c should have read: '(c) The flow lines that show the direction....'

The citation of 'Supplementary Fig. 4C,B' in the first paragraph under the heading 'The supracellular distribution of RhoA activity mirrors the cartography of forces' should have read 'Fig. $4 \mathrm{~b}$ and Supplementary Fig. 4C'.

The page ranges for refs 17, 28, 44, 46 were missing; they are 15895-15900, 1313-1323, 6582-6591 and 1836-1843, respectively.

All these errors have been corrected in the online versions of the Article. 